Cómo citar este trabajo: Martín Duque, C., \& Morère-Molinero, N. (2019). La evaluación de la capacidad de carga perceptual en el Camino de Santiago Francés: una aproximación cuantitativa. Boletín de la Asociación de Geógrafos Españoles, 82, 2682, 1-33. http://dx.doi.org/10.21138/bage.2682

\title{
La evaluación de la capacidad de carga perceptual en el Camino de Santiago Francés: una aproximación cuantitativa
}

\author{
Analysis of social carrying capacity of the French Way \\ for the Camino de Santiago: a quantitative approach
}

\section{Clara Martín Duque}

cmartidu@nebrija.es

Departamento de Turismo

Universidad Antonio de Nebrija (España)

\author{
Nuria Morère-Molinero \\ nuria.morere@urjc.es \\ Grupo de Investigación de Excelencia Methaodos \\ Metodología aplicada a las Ciencias Sociales \\ Universidad Rey Juan Carlos (España)
}

\section{Resumen}

El camino de Santiago francés es el itinerario de Santiago más transitado. El aumento constante de turistas en la ruta ha provocado que se empiecen a escuchar las primeras voces críticas por la masificación de la ruta. Esta problemática unida a las características propias de la ruta, nos ha llevado a plantear el análisis de la capacidad de carga perceptual del Camino de Santiago francés. Para ello se ha diseñado una investigación cuantitativa dirigida a las personas que realizan la ruta. Las 385 respuestas obtenidas nos han permitido determinar que el Camino de Santiago Francés está masificado y se detectan problemáticas y cambios que pueden afectar a la identidad del itinerario a largo plazo. 
Palabras clave: territorio; Santiago de Compostela; turismo cultural; masificación; capacidad de carga social.

\begin{abstract}
The Camino de Santiago's French Way is more heavily transited by visitors and tourists than any other route associated with the iconic pilgrimage. Nowadays, the number of tourists who opt to walk this route is on the rise, voices have been raised in alarm at the excessive influx of tourists. The goal of this essay is to analyze the social carrying capacity of Camino de Santiago's. The results revealed by our quantitative analysis have allowed us to determine that the Camino de Santiago's French Way is overcrowded and reveal problems and early changes that may affect the itinerary in the long run.
\end{abstract}

Key words: territory; Santiago de Compostela; Cultural Tourism; overcrowding; social carrying capacity.

\title{
1 Introducción
}

El turismo se ha ido conformando con el paso del tiempo en una actividad de gran relevancia por su dimensión económica. Si nos atenemos a los datos estadísticos que regularmente se ofrecen a nivel internacional, se podrá comprobar que no ha dejado de crecer, desde mediados del siglo XX. Solo en contadas ocasiones, coincidiendo con conflictos bélicos o grandes recesiones económicas, dicho crecimiento se ha desacelerado o se ha tornado en descenso (Butler, 2004). Por tanto, se observa una tendencia progresivamente ascendente (OMT, 2018) con unas previsiones de crecimiento para 2030 muy alentadoras, según la OMT (2017), llegando a alcanzar 1,8 miles de millones de turistas en todo el mundo.

En España, si se analizan los datos de los turistas no residentes de los últimos catorce años, se observa también un incremento progresivo, solo interrumpido en los años 2008 y 2009 como causa de la crisis económica internacional. Sin embargo, una vez retomada la tendencia ascendente, las previsiones de crecimiento indicaban que en el 2017 se iba a rebasar los 80 millones de turistas (Figuerola, 2017), dato que se confirmó primeramente en 2017 con los casi 82 millones de 2017 (INE, 2017) y se afianzó en 2018 con los 82,77 millones registrados (INE, 2018).

Si bien es cierto que la mayoría de estos turistas elige un turismo de sol y playa frente a un 15,7\% que elige el turismo cultural (CulturaBase, 2018) existen algunos productos de turismo cultural exitosos como es el caso del Camino de Santiago. Un itinerario que no ha dejado de aumentar en los últimos años (Oficina del peregrino, 2017) y que incluso ha experimentado situaciones de masificación (Gracia, 2005; Almeida, 2006; Santos, 2006; Tresserras, 2007; Fiol, 2010; Porcal et al., 2012; Alvarado, 2013; Martín-Duque, 2017). Dichas aglomeraciones, pueden generar 
impactos negativos en el destino tales como degradación en los recursos culturales y naturales, así como reacciones negativas en los residentes (Coccossis, 2004; Troitiño \& Troitiño, 2016).

A pesar de la relevancia de esta posible masificación para la pervivencia del Camino a largo plazo, no existen apenas estudios que aborden esta temática, seguramente por la serie de dificultades que plantea, tanto desde el punto de vista conceptual como metodológico al no existir estudios empíricos que analicen el tema en profundidad. De hecho, anteriores publicaciones de tipo cualitativo hacían hincapié en la necesidad de realizar estudios que evaluasen la capacidad de carga del Camino (Martín-Duque, 2017). Los expertos entrevistados en el citado estudio indicaban que, dada las características de la ruła, configurada como un itinerario multi-entrada y multidireccional recorrida por turistas y peregrinos con motivaciones diversas (Murray \& Graham, 1997; Lois-González \& Santos, 2014; López et al., 2017), la metodología más adecuada para evaluar la capacidad de carga del itinerario era la perceptual, que permite acercarse a los impactos que se producen en recursos dinámicos como es un itinerario. Así, teniendo en cuenta estas consideraciones, el presente artículo plantea como objetivo fundamental la evaluación de la capacidad de carga perceptual del Camino de Santiago Francés. Llevaremos a cabo una revisión de la literatura especializada y determinaremos una serie de variables que nos ayudarán a diseñar y realizar el estudio empírico. El estudio se centra en el análisis de los últimos 100 km. (desde Sarria a Santiago de Compostela) donde planteamos una perspectiva de análisis distinta, distanciándonos ligeramente de perspectivas economicistas, y centrándonos en estudios sociales, más próximos al peregrino y a la población local.

\section{El Camino de Santiago Francés y su vinculación con el turismo}

El Camino Francés es, de todos los caminos de Santiago históricos, el más transitado (Santos, 2006; Tresserras, 2007; Alonso, 2009; Millán et al., 2010), más concretamente un 56,9\% de los peregrinos eligen este itinerario (Oficina del Peregrino, 2017). Su nombre proviene de las cuatro rutas que marcan el comienzo del itinerario en territorio francés y su trazado comprende más de 2.000 km (Lois \& Medina, 2003) aunque es en los últimos 100 km (desde Sarria hasta Santiago) donde más personas se concentran (Fraternidad Internacional del Camino de Santiago, 2014; Martín-Duque, 2017). La Compostela va a ser una de las razones de la congestión de este último tramo, pues para conseguirla es necesario recorrer, al menos, $100 \mathrm{Km}$ a pie o $200 \mathrm{Km}$ en caso de realizar el recorrido en bicicleta (Rodríguez \& Singul, 2004).

Es destacable también su pervivencia a lo largo de la historia, desde la Edad Media hasta la actualidad (Santos, 2006; Alonso, 2009; Santos, 2012) con ciertas fluctuaciones en cuanto a su éxito de afluencia (Santos \& Lois, 2011; Lois \& López, 2012; López \& Lois, 2015) hasta su revitalización a mediados del siglo XX (Álvarez, 1999; Santos, 2006). En la actualidad, es una ruta muy transitada y se ha transformado en una atracción turística y cultural (Amaro, Antunes \& 
Henriques, 2018). En ese sentido, es considerado un caso paradigmático y se han desarrollado variadas líneas de investigación y de análisis, tanto desde una perspectiva internacional (Maak, 2009; López \& Lois, 2015) como desde perspectivas autonómicas (Tresserras, 2007). De él se han realizado estudios referentes a la protección del patrimonio (Bermejo, 2002; Álvarez, 2007) o a su declaración como itinerario cultural en 1987 por el Consejo de Europa (ICOMOS, 2006). También se ha abordado temas como el del camino como factor de desarrollo (Santos, 2006; Precedo et al., 2007), la comunicación en el camino (Rodríguez et al., 2011), así como sobre otros caminos de Santiago (Martín, 2014).

Sin embargo, los análisis más relevantes para este estudio son los que se refieren a los cambios que ha experimentado la ruta a lo largo de la historia, tanto desde el punto de vista de la propia ruta en relación con el territorio como en lo que afecta a los viajeros. Respecto a la ruta es muy ilustrativo el modelo propuesto por Murray y Graham (Figura 1), para percibir esta evolución. En concreto el Camino se podría encuadrar a la etapa más desarrollada de este modelo, es decir, una ruta que refleja la heterogeneidad y diversidad del peregrinaje moderno por tener varios usos1; que ha perdido, en gran parte, la sacralidad de sus orígenes; que es recorrida por peregrinos y turistas con motivaciones muy heterogéneas.

Figura 1. Configuración de una ruta de peregrinaje basada en el turismo ( 5 a etapa de desarrollo)

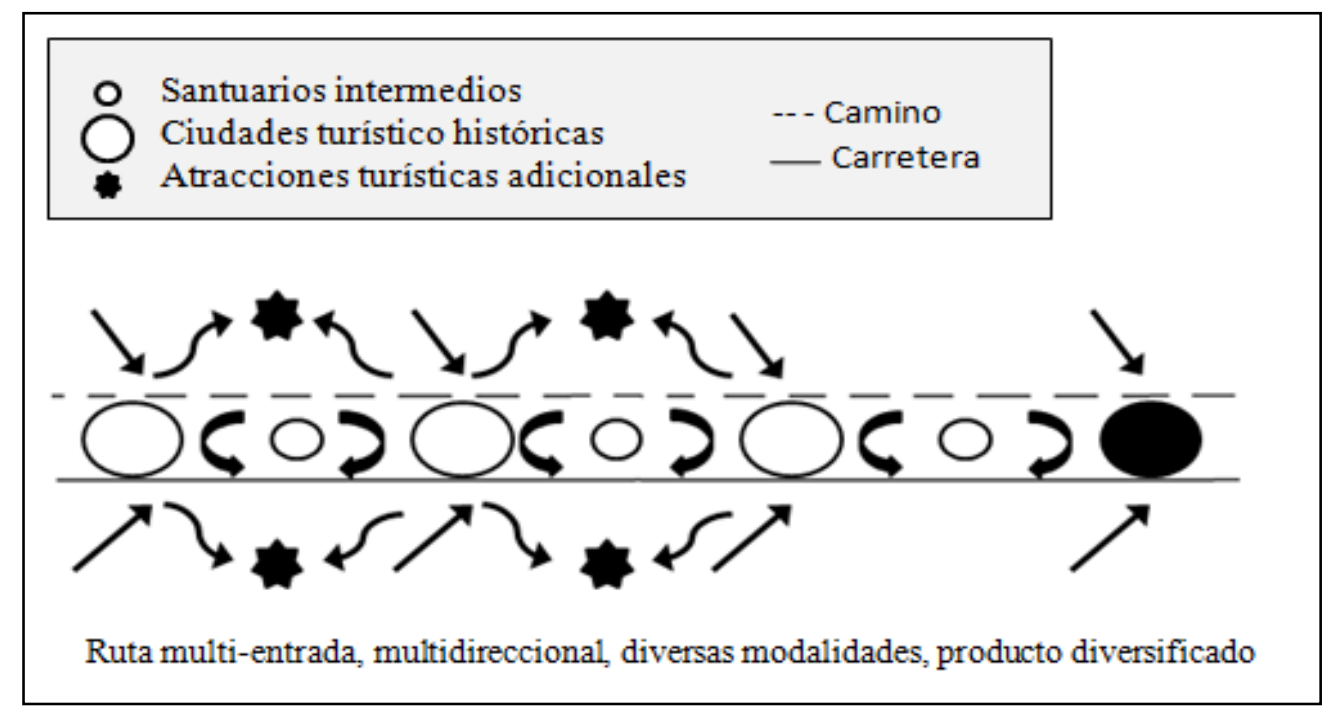

Fuente: elaboración propia a partir de Murray y Graham (1997)

El otro factor es la transformación del perfil del peregrino, desde los últimos años del siglo XX hasta la actualidad. Esta transformación se ha producido fundamentalmente en cuanto a las motivaciones del peregrino, pues si bien tradicionalmente la peregrinación a Santiago se ha relacionado con una

1 El Camino, según Precedo et al. (2007) tiene muchos sentidos "desde una Camino penitencial de peregrinación o una ruta cultural, pasando por una ruta de senderismo o un Camino esotérico, o incluso una alternativa a una sociedad materialista, o como una moda más" ( Precedo et al., 2007, p. 214). 
motivación exclusivamente religiosa (Millán et al., 2010), en la actualidad el peregrino es atraído por motivos como la cultura, el deporte, la naturaleza o por motivos espirituales (Graham y Murray, 1997; Porcal et al., 2006; Precedo et al. 2007; Granero et al., 2008; Maak, 2009; Leira, Rego \& Santos, 2010; Hernández, 2011; Santos \& Lois, 2011; Martín, 2014; López et al., 2017; Amaro et al., 2018). Los peregrinos del Camino de Santiago son personas de características y motivaciones distintas que, por alejarse de la acepción tradicional de peregrino (Santos y Lois, 2011), en este artículo nos referiremos a ellas como "personas que realizan el camino", "caminantes" (Santos, 2006) o "turistas" al considerarse el camino como un producto turístico (Santos y Lois, 2011)2.

En el mismo sentido, en lo que a sus infraestructuras se refiere, el francés, es de los caminos mejor acondicionados no solo por la amplia red de albergues y alojamientos turísticos de todo tipo sino por el buen estado de las vías que lo componen y la señalización existente a lo largo de todo el recorrido (Celeiro, 2014). Estas buenas condiciones infraestructurales han atraído a un gran número de personas que han ido aumentando año tras año. Más concretamente en la última década (desde 2004), tal y como se observa en la Figura 2 se ha producido un aumento paulatino en el número de peregrinos tanto nacionales como internacionales (Oficina del Peregrino, 2018) que no se ha visto frenado por coyunturas económicas adversas como la experimentada como consecuencia de la crisis de 2008. Además, estas cifras tan positivas han ido acompañadas por un nivel de satisfacción alto por parte de los peregrinos (Santos \& Lois, 2011) por lo que se puede definir como un producto turístico exitoso.

Figura 2. Evolución en el número de peregrinos

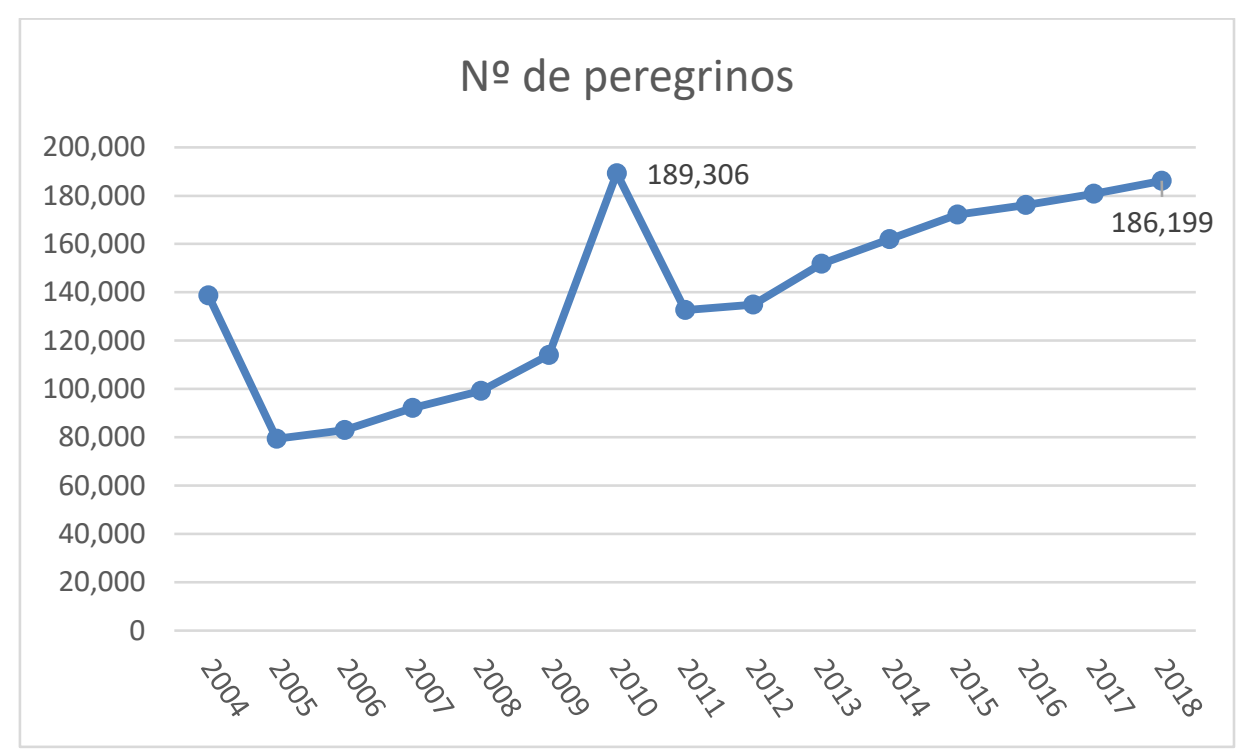

Fuente: elaboración propia a partir de los datos de la Oficina del Peregrino (2018)

2 Se ha preferido este término general al estar analizando un producto turístico, pero queremos señalar que existe una larga bibliografía en torno a la diferenciación entre peregrinos y turistas en la era actual recogida y analizada: Collins-Kreiner (2010). 
Sin embargo, estas cifras han demostrado, que aunque pueden ser beneficiosas de cara a incentivar iniciativas locales (Montes, 2015), también indican el peligro del aumento continuo del número de caminantes. Dicho riesgo radica, por un lado, en la excesiva turistificación de la ruta (Gracia, 2005; Martín-Duque, 2017) y en la pérdida de su sentido original ${ }^{3}$ y degradación de recursos (Fraternidad Internacional del Camino de Santiago, 2014) pero, sobre todo, en la masificación del itinerario y el consecuente empeoramiento de la experiencia de las personas que transitan (Almeida, 2006; Santos, 2006; Tresserras, 2007; Fiol, 2010; Porcal, Díez \& Junguitu, 2012).

No obstante, no se puede afirmar que haya existido una despreocupación por parte de la administración autonómica en cuanto a la protección del camino. Desde el punto de vista de la política turística, se han desarrollado diferentes instrumentos de planificación y ordenación del territorio desde los años 70 hasta la actualidad. Incluso en Galicia se desarrolla, en 1996, la Ley de Protección de los Caminos y, en 2016, la Ley de Patrimonio Cultural de Galicia que, a pesar de no conseguir implementar un Plan Especial regional, reconocen la posibilidad de catalogar nuevas rutas. Este hecho, favorece que las personas que realizaron el Camino a partir de 2016, en territorio gallego pudieran elegir caminos alternativos para llegar a Santiago. Sin embargo, pese a los esfuerzos que realizan muchas de las autonomías por las que transcurre el Camino Francés, así como las iniciativas existentes para coordinar a los diferentes actores, tales como el Consejo Jacobeo o la Asociación de Municipios del Camino de Santiago, Somoza \& Lois (2017) apuntan que no hay una política común o una coordinación entre ellas que permitan resolver los problemas del camino de una forma uniforme.

Teniendo en cuenta estas consideraciones, el presente artículo se propone como objetivo fundamental la evaluación de la capacidad de carga perceptual del Camino de Santiago Francés, mediante la revisión de la literatura especializada y la determinación de una serie de variables que nos ayudarán a diseñar y realizar el estudio empírico.

3 El patrimonio cultural es uno de los principales elementos identitarios que nos rodea. Si bien el patrimonio cultural es un testimonio de por sí en evolución dentro de las transformaciones de la sociedad, la irrupción del factor turismo y sus impactos están produciendo demasiadas rápidas transformaciones que, a veces, pueden degradarse, no correspondiendo con la propia evolución local y social (Gravari-Barbas, Bourdeau \& Robinson ,2015). En el caso del Camino francés de Santiago, estamos ante una muy larga evolución no sólo desde el siglo XII sino incluso en el siglo XX, y la masificación puede ser una de las causantes de esta rapidísima transformación que, incluso, provocaría su pérdida de atractivo para los caminantes, cualquiera que sea su motivación principal. De ahí la importancia de tener datos empíricos sobre la masificación del Camino porque permite también medir las transformaciones y los cambios en la identidad. Esta preocupación ha desarrollado recientemente una importante bibliografía especialmente para el Patrimonio Mundial al que pertenece el Camino de Santiago francés. 


\section{La capacidad de carga perceptual como instrumento de evaluación de recursos dinámicos}

La utilización de la metodología de estimación de la capacidad de carga, en sus primeros años de vida, nace de la necesidad de la demarcación de límites estrictos de uso en los espacios recreativos. Es, en este momento, cuando se plantean las primeras teorías acerca de la existencia de "un número mágico" y "universal" que indicase la cantidad exacta de personas que pudiera acudir a un determinado lugar sin degradarlo.

Sin embargo, enseguida se desencadenan las primeras críticas dada la poca libertad que otorgaba a gestores y planificadores turísticos a la hora de tomar decisiones (Gunn, 1979; Getz, 1983; O’Reilly, 1986; Shelby \& Herbelein, 1986; Williams y Gill, 1994; Butler, 1996; Watson \& Kopachevsky, 1996; Mc. Cool \& Lime, 2001; Echamendi, 2001; Pedersen, 2002; Mansfeld \& Jonas, 2005), exponiendo otros planteamientos. Volviendo al "número mágico y universal", a pesar de las críticas que suscita, López y López (2008) aseguran que el método numérico puede ser útil en lugares acotados, es decir en recursos que tengan bien marcados sus límites, como edificios históricos o parques naturales. En el caso que nos ocupa en el presente estudio, en las rutas turísticas y más concretamente en el Camino de Santiago, estos métodos numéricos no serían de demasiada utilidad pues no se trata de un recurso acotado sino de muchos recursos unidos por unas vías abiertas como son los senderos que componen dichas rutas (Martín-Duque, 2017).

Por todo ello, se considera que la metodología más adecuada para medir la capacidad de carga de un recurso de estas características, es la perceptual dirigida a la percepción de la masificación o de las aglomeraciones "crowding perception". 4

Shelby y Heberlein (1986) son los autores más relevantes de este enfoque y base de nuestra propuesta de análisis. Sus estudios se centran en la percepción de la masificación ${ }^{5}$ que, al ser una variable más ligada al número de personas, puede ser un mejor indicador que la satisfacción; ésta, en muchos casos, no se relaciona exclusivamente con el nivel de uso sino con otros factores como la experiencia esperada.

Por otra parte, en el campo de la percepción de las aglomeraciones y del comportamiento derivado de esa percepción, existe toda una literatura previa relacionada con una corriente psicológica (Stokols, 1972; Stokols, Rall, Pinner \& Schopler, 1973) que estudia las posibles causas

4 La percepción de la masificación se define como la evaluación negativa de los niveles de uso o encuentros con otros visitantes (Shelby \& Herbelein, 1986, p. 62).

5 Para medir la percepción de la masificación, Shelby y Herbelein (1986) proponen preguntar directamente a los visitantes "en qué medida sienten la masificación" y les ofrecen una escala de respuesta del 1 al 9 (donde 1-3 representa no masificado; del 3 al 5 parcialmente masificado; del 5 al 7 moderadamente y del 7 al 9 extremadamente masificado). 
y consecuencias de las aglomeraciones en el ser humano. Entre las variables que Stokols et al. (1973) enuncian como más determinantes a la hora de percibir la masificación, destacan el estatus educacional y socioeconómico del individuo, el tamaño del grupo, las tradiciones culturales del individuo y la relación que tenga con el espacio, es decir si es residente en la zona, en la región o visitante. Dichas variables van a ser adoptadas en muchos de los estudios posteriores (Kalisch, 2012; Neuts \& Nijkamp, 2012) y, además, se incluirán tipologías: sociodemográficas (Kuentzel \& Heberlein, 2003; Kalisch, 2012; Gonson, Pelletier, \& Alban, 2018), temporales (Tarrant \& English, 1996; Shelby \& Vaske, 2007; Kailisch, 2012), espaciales (Shelby \& Vaske, 2007; Vaske \& Shelby, 2008) o motivacionales (Neuts \& Nijkamp, 2012).

Otra de las variables que señalan como destacables e influyentes en nuestra percepción conceptual son las expectativas (Shelby, 1976); cuando una experiencia difiere de lo que se pensaba como apropiado, dicha experiencia se percibe como negativa. Los visitantes serán más susceptibles a las aglomeraciones si basan sus expectativas en una experiencia anterior en la que el lugar visitado no tenía tanta gente (Vaske, Donnelly y Heberlein, 1980; Lee y Graefe, 2003; Arnberger \& Haider, 2007; Navarro et al., 2013, Gonson et al., 2018). En lo que se refiere a las consecuencias que se pueden desencadenar en los individuos, varios autores (Stokols, 1972; Stokols et al., 1973) afirman que, de no poder mitigar la sensación de masificación, se pueden ocasionar situaciones de estrés.

Así pues se trata, de hecho, de un modelo para medir la capacidad de carga que prioriza los factores sociales y psicológicos más que los físicos, pues según Shelby (1980) los primeros nos aportan mucha más información sobre la experiencia del visitante. Es un sistema, además, que va a priorizar la percepción y las opiniones de los grupos de interés por delante de la información sobre el entorno físico, dando así una mayor importancia al factor humano. De esta manera, en función de esta serie de condicionantes y de estudios posteriores sobre el tema objeto de estudio, se han sintetizado una serie de variables encaminadas a evaluar la capacidad de carga perceptual en el Camino de Santiago Francés.

\subsection{Variables utilizadas para medir la percepción de la masificación}

La mayoría de los estudios que abordan la capacidad de carga perceptual buscan evaluar la percepción de masificación mediante el análisis del porcentaje de personas, ya sean visitantes o residentes, que perciben el lugar como masificado. En este sentido la mayoría de ellos siguen los criterios marcados por Shelby y Heberlein (1986), que indican que la capacidad de carga se ha excedido si más de dos tercios de los visitantes se sienten masificados. Si bien la mayor parte de los estudios utilizan la variable antes mencionada de percepción de masificación, existen otras variables para medirla que merecen ser revisadas y consideradas. Shelby y Heberlein (1986) añaden la medición del nivel de contacto, el cual se mide preguntando a los encuestados cuántas veces se encuentran con grupos de turistas y cuáles son las percepciones acerca de estos encuentros. Sin 
embargo, tal y como indican Tarrant y English (1996), este dato solo es posible recabarlo en una situación de baja densidad siendo menos útil en espacios abiertos y de alta densidad. Por ello, expertos como Manning et al., 2005 o Navarro et al. (2013) recurren a otros procedimientos como acudir a instrumentos como la metodología PAOT "People At One Time" que indica cuál es el umbral de capacidad de carga que tienen las personas objeto de estudio.

De cualquier modo, lejos de evaluar la percepción de masificación la gran parte de investigaciones especializadas van más allá y tratan de evaluar los impactos que esta masificación genera en el destino o recurso en cuestión y si, de algún modo, esto puede influir en su actitud presente y futura (Kuentzel \& Heberlein, 1992; Arnberger \& Brandenburg, 2007), acercamiento que hemos seguido y así podríamos identificar si estos impactos afectarían al umbral de capacidad de carga de las personas objeto de estudio.

Por último otro enfoque en muchos de los estudios trata de evaluar si estos umbrales de percepción de masificación varían en función de las características del turista, el viaje o el ámbito de estudio, incluso tratando de identificar la existencia de diferentes perfiles de viajeros en función de esa percepción de masificación y de esos umbrales (Arnberger \& Haider, 2005; Navarro et al., 2013). Así pues, se ha podido establecer la Tabla 1 con la correspondencia entre objetivos y variables de la capacidad de carga perceptual, base de nuestro análisis.

Tabla 1. Objetivos comunes de los estudios de capacidad de carga perceptual

\begin{tabular}{|c|c|}
\hline OBJETIVOS & VARIABLE DE MEDICIÓN \\
\hline Existencia de masificación & - Percepción de masificación o demasiadas personas. \\
\hline Efectos de la masificación & - Impactos de la masificación. \\
\hline Umbrales de capacidad de carga & $\begin{array}{l}\text { - Estándares de evaluación. } \\
\text { - } \quad \text { Disposición a abandonar. } \\
\text { - Actitud futura. }\end{array}$ \\
\hline $\begin{array}{l}\text { Diferentes umbrales de capacidad } \\
\text { de carga }\end{array}$ & $\begin{array}{l}\text { - Influencia de características socio-demográficas, del } \\
\text { viaje y del ámbito de estudio en la percepción de } \\
\text { masificación. } \\
\text { - Existencia de diferentes perfiles de personas en } \\
\text { función de umbrales de capacidad de carga. }\end{array}$ \\
\hline
\end{tabular}

Fuente: elaboración propia

\subsection{Estudios de capacidad de carga realizados en torno al Camino de Santiago}

La mayoría de investigaciones acerca de la capacidad de carga relacionadas con el Camino de Santiago no tienen el itinerario como protagonista sino ciudades (Almeida, 2006) o recursos 
específicos que forman parte de él (Gigirey, 2003; García \& De la Calle, 2012). No obstante, en 2018, se ha publicado el adelanto de una investigación, coordinada por Fernández y Riveiro (2018), orientada a evaluar el impacto socioeconómico del Camino de Santiago, donde se arrojan algunos datos sobre la capacidad de carga del itinerario en Galicia aunque no es el propósito fundamental de la obra.

El estudio de Almeida (2006) se centra en el caso de la ciudad de Santiago y se propone medir el malestar de los residentes mediante el análisis de la oferta, la percepción de masificación de los visitantes y la valoración de los visitantes sobre el trato recibido por los residentes. Para ello realiza una encuesta dirigida a excursionistas, turistas y peregrinos venidos de los diferentes Caminos de Santiago. Los ítems peor valorados fueron aquellos relacionados con las infraestructuras existentes como "problemas de acceso a Santiago y aparcamiento" o algunos problemas ambientales como "el ruido". Sin embargo en este estudio se destaca que en general los visitantes tienen una percepción positiva de la ciudad destacando aspectos como "la amabilidad de los residentes" o la autenticidad del destino". Mientras que la percepción de masificación de los sujetos encuestados se mostró mayoritariamente negativa (entre un 80 y 90 \% contestaron "no") es decir, no perciben la ciudad como masificada ni en temporada alta ni en la baja.

Aunque los resultados obtenidos en el estudio de Almeida (2006) acerca de la experiencia de los turistas en la catedral son positivos, este punto, sigue siendo señalado como uno de los más congestionados de la ciudad. Por ello, estudios más exhaustivos sobre la catedral, como los de García y De la Calle (2012) y Gigirey (2003), nos permitirán entender mejor la problemática entorno a este recurso.

Gigirey (2003), estudia el fenómeno de los impactos generados en la catedral desde el punto de vista de los residentes, estableciendo, en función de las reacciones de éstos, tres clusters distintos: el cluster "abrazo" que recibe de forma muy positiva al turista; el cluster "mantenimientos de límites" que recibe al turista con determinadas reticencias y estableciendo límites psicológicos al turismo; y el cluster "ajuste forzado" que cambian su comportamiento habitual para adaptarse a la realidad.

García y De la Calle (2012), en cambio, aplicarán en la catedral un procedimiento de análisis basado en la metodología aplicada por Cifuentes (1996) en Galápagos, realizando conteos y analizando el espacio receptor así como el perfil del visitante. Esta técnica, permitió calcular que el número óptimo de visitantes simultáneos era de 1000 personas por lo que no se recomendaban más de 16000 visitas diarias.

Conjuntamente, se trataron de identificar los impactos que se estaban ocasionando en el templo entre los que destacan: la concentración de personas en determinados espacios del templo, la incompatibilidad de usos turísticos y religiosos, y el comportamiento inapropiado de visitantes que 
afecta a la conservación y seguridad del templo y al deterioro de la calidad de la visita (García \& De la Calle, 2012). Además de estas investigaciones, recientemente, Fernández y Riveiro (2018) han publicado los resultados de un estudio sobre "el impacto socioeconómico del Camino de Santiago" centrado en Galicia. A pesar de que los datos no han sido publicados completamente con su metodología, el estudio indica que la satisfacción de residentes de Pedrafita do Cebreiro y Melide, así como la de los caminantes (en Santiago de Compostela) es muy alta y la capacidad de acogida (alojamiento) es todavía muy alta aunque existen densidades altas en determinados meses del año y etapas del camino.

Tabla 2. Investigaciones realizadas en capacidad de carga en torno al ámbito objeto de estudio

\begin{tabular}{|c|c|c|c|c|}
\hline $\begin{array}{l}\text { AUTORES } \\
\text { (AÑO) }\end{array}$ & $\begin{array}{l}\text { ÁMBITO } \\
\text { ESTUDIO }\end{array}$ & OBJETIVOS & INSTRUMENTO & RESULTADOS \\
\hline $\begin{array}{l}\text { Almeida } \\
(2006)\end{array}$ & $\begin{array}{l}\text { Santiago de } \\
\text { Compostela }\end{array}$ & $\begin{array}{l}\text { Evaluar la calidad } \\
\text { de la experiencia } \\
\text { de la visita de los } \\
\text { visitantes a la } \\
\text { ciudad de Santiago }\end{array}$ & $\begin{array}{l}\text { Encuestas a } \\
\text { visitantes }\end{array}$ & $\begin{array}{l}\text { Problemas: accesos de la } \\
\text { ciudad y ruido. } \\
\text { No se percibe } \\
\text { masificación }\end{array}$ \\
\hline $\begin{array}{l}\text { Gigirey, } \\
2003\end{array}$ & $\begin{array}{l}\text { Catedral } \\
\text { Santiago de } \\
\text { Compostela }\end{array}$ & $\begin{array}{l}\text { Identificar los } \\
\text { diferentes flujos de } \\
\text { turistas y analizar la } \\
\text { presión que } \\
\text { generan en la } \\
\text { ciudad. }\end{array}$ & $\begin{array}{l}\text { Encuestas a } \\
\text { residentes }\end{array}$ & $\begin{array}{l}\text { 3Clusters: "abrazo", } \\
\text { "mantenimientos de } \\
\text { límites" y "ajuste forzado" }\end{array}$ \\
\hline $\begin{array}{l}\text { García y } \\
\text { De la Calle } \\
(2012)\end{array}$ & $\begin{array}{l}\text { Catedral } \\
\text { Santiago de } \\
\text { Compostela }\end{array}$ & $\begin{array}{l}\text { Análisis de la } \\
\text { capacidad de } \\
\text { carga y flujo de } \\
\text { visitantes de la } \\
\text { catedral de } \\
\text { Santiago de } \\
\text { Compostela }\end{array}$ & $\begin{array}{l}\text { Conteos y } \\
\text { encuestas a } \\
\text { visitantes }\end{array}$ & $\begin{array}{l}\text { Establecimiento de un } \\
\text { número máximo } \\
\text { aproximado de } \\
\text { personas/día (16 000) } \\
\text { Problemas con las } \\
\text { aglomeraciones por } \\
\text { simultaneidad de usos y } \\
\text { concentración excesiva en } \\
\text { determinados puntos de la } \\
\text { catedral que pueden } \\
\text { afectar a su conservación }\end{array}$ \\
\hline $\begin{array}{l}\text { Fernández } \\
\text { y Riveiro } \\
\text { (2018) }\end{array}$ & $\begin{array}{l}\text { Camino de } \\
\text { Santiago } \\
\text { Francés } \\
\text { (trazado en } \\
\text { territorio } \\
\text { gallego) }\end{array}$ & $\begin{array}{l}\text { Estudio del impacto } \\
\text { socioeconómico del } \\
\text { Camino de } \\
\text { Santiago }\end{array}$ & $\begin{array}{l}\text { Encuestas a } \\
\text { turistas y } \\
\text { residentes }\end{array}$ & $\begin{array}{l}\text { La percepción de alta } \\
\text { afluencia de los } \\
\text { peregrinos no modifica su } \\
\text { conducta } \\
\text { La capacidad de carga } \\
\text { real es muy superior al de } \\
\text { los peregrinos que } \\
\text { realizan la ruta }\end{array}$ \\
\hline
\end{tabular}

Fuente: elaboración propia 
En general los estudios anteriormente comentados, se han realizado o bien en recursos cerrados o bien en un solo punto del Camino de Santiago, como es el caso del estudio de Fernández y Riveiro (2018) que centra el estudio de la percepción de los caminantes en la última etapa (Santiago de Compostela). A diferencia, de las investigaciones anteriormente planteadas, el presenta trabajo de investigación ha planteado una metodología de trabajo de campo en la que se trata de recoger un conjunto de variables orientadas a evaluar la capacidad de carga perceptual del camino en los puntos más importantes de los últimos 100 Km de Camino de Santiago Francés en temporada alta.

\section{Metodología}

Para evaluar la capacidad de carga perceptual de los últimos 100 km del Camino de Santiago Francés se ha acudido a una metodología de tipo cuantitativo, siendo el cuestionario el instrumento elegido para la recolección de datos. Dichos cuestionarios se realizaron de forma personal a las personas que estaban realizando el Camino en el mes de agosto de 2014.

\subsection{Muestra}

El diseño muestral de las encuestas se ha realizado con la realización de un muestreo incidental no aleatorio polietápico. Así, en una primera etapa se han seleccionado los municipios por los que transcurren los últimos 100 km del Camino de forma incidental, es decir, escogiendo aquellos que recorren las principales etapas. Por otro lado, en una segunda etapa no aleatoria, se ha acudido a los lugares más concurridos de caminantes de estos municipios, es decir, albergues, hoteles, restaurantes o plazas centrales.

Tabla 3. Ficha técnica encuesta a personas que realizan el Camino

\begin{tabular}{|l|l|}
\hline \multicolumn{1}{|c|}{ UNIVERSO } & \multicolumn{1}{|c|}{ INFINITO (personas que realizan el Camino de Santiago Francés) } \\
\hline Tipo de entrevista & Encuesta autoadministrada realizada de forma presencial \\
\hline $\begin{array}{l}\text { Procedimiento de } \\
\text { muestreo }\end{array}$ & Polietápico \\
\hline Tamaño muestral & 385 \\
\hline $\begin{array}{l}\text { Error muestral } \\
\text { Fecha de trabajo de } \\
\text { campo }\end{array}$ & Agosto 2014 \\
\hline
\end{tabular}

Fuente: elaboración propia.

El universo está formado por 172243 personas que son las que transitaron por el Camino de Santiago Francés en 2014, por lo tanto nos encontramos ante un universo infinito del que se han 
obtenido un total de 385 respuestas siendo el error muestral de $\pm 5 \%$ para un nivel de confianza del 95 \%, bajo el supuesto de máxima indeterminación ( $p=q=50$ \%).

El perfil de la muestra está conformado casi por la misma proporción de hombres (49 \%) y mujeres (51\%), de éstos una gran mayoría (75\%) son de nacionalidad española y el 25 \% restante son no residentes, entre los cuales destacan los italianos que representan el 13\% de la muestra, seguidos de lejos por los alemanes (2\%) y con un $1 \%$ los portugueses, franceses e ingleses.

Una gran parte de los residentes proceden de la Comunidad Valenciana y la Comunidad de Madrid con una cuota del 21 \% respectivamente, seguidos muy de cerca por Cataluña (20 \%) y a cierta distancia por Andalucía (9 \%) y Castilla León (6\%). En cuanto a la edad, la mayor parte de la muestra (53 \%) se concentra en el intervalo de 19 a 31 años seguido de lejos por aquellos que tienen entre 32 y 45 años $(25,5 \%)$.

\subsection{Procedimiento}

El trabajo de campo se realizó en los últimos 100 km (desde Sarria a Santiago de Compostela) ${ }^{6}$ y en temporada alta pues coincide con las localizaciones y el momento del año donde según los expertos consultados se producen las mayores aglomeraciones. Más concretamente la época escogida para realizar las encuestas fue el mes de agosto de 2014 pues se identifica también, como el periodo en donde confluyen más personas en el recorrido.

La mayor parte de las encuestas de las personas que realizan el Camino se concentraron en los municipios de Santiago de Compostela, el municipio más poblado, y Palas de Rei (30\%) aunque, por lo general, los peregrinos se mostraron muy receptivos a la hora de contestar la encuesta, registrando una tasa de respuesta en torno al 98 \%. En el municipio de Sarria se registró una menor tasa de respuesta pues muchos de los peregrinos comenzaban su Camino en esta localidad y no podían hablar de su experiencia

La modalidad de encuesta seleccionada fue la encuesta personal pues permite al investigador aclarar cuestiones complejas o que no se entiendan, recoger información suplementaria pero, sobre todo, motivar al entrevistado y despertar su interés, obteniendo así un mayor número de respuestas (Gutiérrez, 2013).

Para la realización efectiva del proceso de encuestación se acudió a los lugares más concurridos de estos municipios, es decir, en la plaza central, puertas de los albergues o calles comerciales.

6 Es importante indicar que, aunque a partir de Arzúa hay caminantes provenientes del Camino Primitivo y del Norte que acceden al trazado francés a través de Melide, las encuestas se han realizado exclusivamente a aquellos que estaban realizando el Camino de Santiago Francés, no obstante la percepción de masificación puede ser más elevada en las últimas etapas por esta cuestión. 
Una vez administrado el cuestionario, se procedió a la codificación de las preguntas para su procesamiento mediante el programa SPSS statistics y posterior análisis de los datos recogidos

Figura 3. Distribución de los cuestionarios por lugar de realización

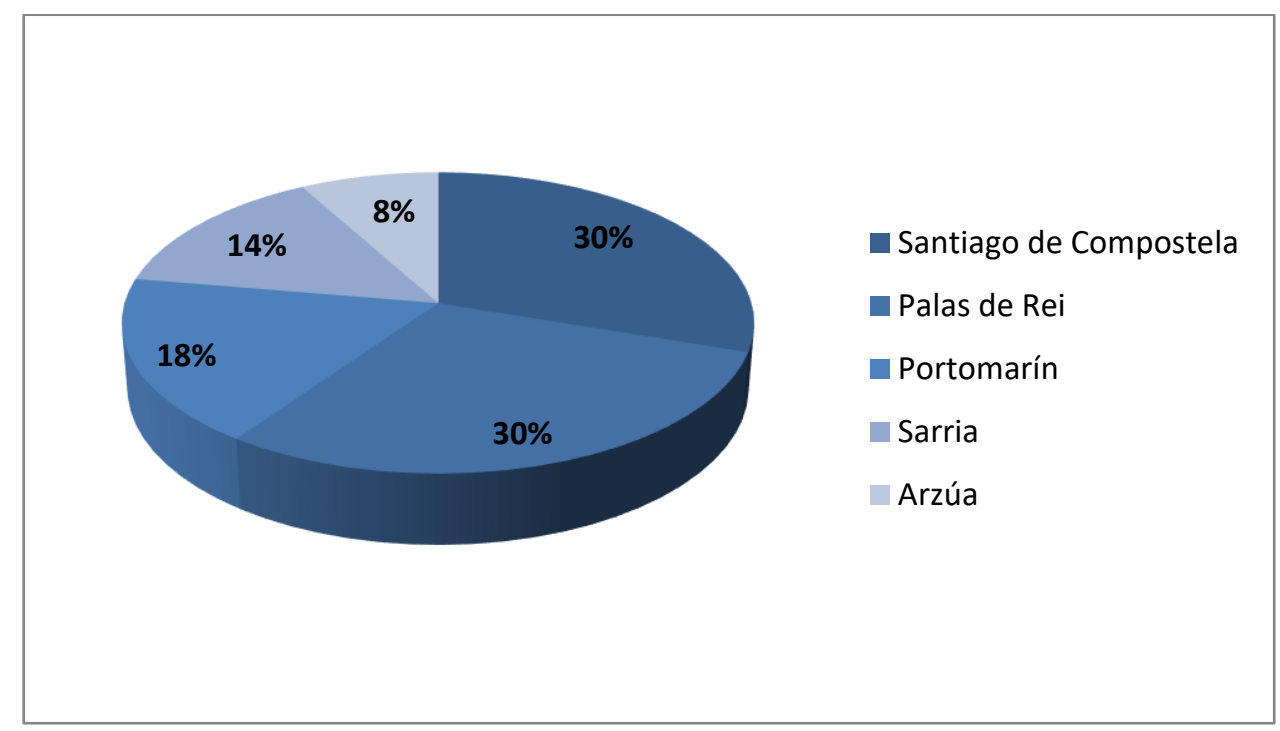

Fuente: elaboración propia

\subsection{Instrumento y análisis}

En cuanto a la estructura de los cuestionarios hay que indicar que se han dividido en tres bloques siguiendo los objetivos que se suelen abordar en los estudios de capacidad de carga perceptual (características del perfil del caminante, percepción y efectos de la masificación y umbrales de masificación) señalados en la Tabla 1.

En el primer bloque se han introducido una serie de cuestiones encaminadas a extraer los datos sociodemográficos del encuestado: género, edad nacionalidad y comunidad autónoma de referencia en caso de residir en España, ocupación y nivel de estudios. De forma posterior se ha profundizado en las variables que caracterizan el viaje de las personas que realizan el Camino (motivación, modo de realización, etc.).

En un segundo bloque se ha tratado de evaluar la percepción de masificación y la percepción de los efectos de esa masificación del Camino a través de una serie de afirmaciones o ítems (variables dependientes) que hacen referencia a los impactos de diversa índole (económicos, medioambientales y sociales), tanto negativos como positivos, que se están produciendo en el Camino y valorados a través de la escala actitudinal de Likert de 5 puntos donde 1 es "muy en desacuerdo" y 5 "muy de acuerdo" (Canales, 2006). Se ha reducido, por tanto, la escala de Shelby \& Herbelein (1986) a una escala de 5 puntos para simplificar y hacer el cuestionario más comprensible al encuestado. 
En cuanto a el análisis de la variable "demasiadas personas" se ha realizado siguiendo el procedimiento de Shelby \& Herbelein (1986) reiterado en el meta-análisis realizado por Shelby y Vaske7 (2007). Así, aunque inicialmente dicha variable pueda ser medida de forma métrica, pudiendo dar al entrevistado opciones de respuesta de escala comprendidas entre 1-9, 1-7 y 15, son muchos los autores posteriores que, con el objetivo de ajustar la percepción de la respuesta de los encuestados a la verdadera realidad de los destinos turísticos, optan por un proceso de dicotomización de dicha variable, inicialmente medida de forma métrica. En concreto, algunos autores han utilizado para ello una escala de medida de 1 a 9 puntos, tomando como puntos de categorización "nada masificado" los valores comprendidos entre 1-2, mientras que el resto de valores, desde 3 hasta 9 son etiquetados como "algo masificado". De una forma menos extrema, se ha optado también por procesos de dicotomización donde desde 1-4 ha sido recategorizado como "algo masificado" y desde 5 hasta 9 como "bastante masificado".

Sin embargo, en nuestra investigación, dado que la escala de respuesta inicialmente tomada para medir de forma métrica dicho fenómeno ha estado compuesta por cinco ítems, parece riguroso desde un punto de vista estadístico recategorizar dicha variable en una nueva variable dicotómica donde la etiqueta de "no masificado" se corresponda con los valores 1 y 2 y la etiqueta "masificado" con los valores 3, 4 y 5.

En el tercer bloque se ha evaluado la actitud tanto presente como futura de los caminantes respecto a la ruta y los estándares de evaluación respecto a la masificación mediante la metodología (PAOT) simplificada que recrea cuatro posibles situaciones de masificación con las que el visitante se puede encontrar con el objetivo de que valoren qué situación no admitiría (Figura 4).

Los resultados se han analizado mediante el programa SPSS (Statistical Package for the Social Sciences), versión 22.0, bajo Windows 8, para su tratamiento estadístico. El análisis se ha llevado mediante un análisis univariable que ha consistido en la utilización tanto de estadísticos de centralización o localización (media aritmética) como de medidas de dispersión (desviación típica, rango, mínimo, máximo), estadísticos básicos que intentan describir la posición de la variable y medir su dispersión.

7 Shelby y Vaske (2007), elaboran un análisis comparativo de los datos agregados de 40 estudios diferentes, realizados entre los años 1975-2005, que tratan de comparar los resultados obtenidos en los mismos en cuanto a la percepción de masificación de cazadores y pescadores. Para poder confrontar las diferentes opiniones sobre la percepción de masificación reducen la escala de 9 puntos propuesta por Shelby y Herbelein (1989) en una variable dicotómica distinguiendo entre aquellos que evalúan la situación como "nada masificada" (cuando se valora del 1 al 2 en la escala de referencia) y los que la evalúan que existe "algún grado de masificación" (cuando se valora la situación del 3 al 9). 
Figura 4. Recreación fotográfica del Camino Francés (PAOT)

para el estudio del volumen de personas admisible a la vez



Fuente: elaboración propia

\section{Resultados}

Los resultados nos muestran, en primer lugar, que las motivaciones que les han llevado a realizar el Camino Francés son, de forma fundamental, espirituales $(21 \%)$, así como para el disfrute de la naturaleza (20 \%) o por una motivación cultural (19\%).

En cuanto a las características del viaje, el medio de transporte más utilizado para la realización del viaje es a pie, lo que supone el 91,7\% de la muestra, seguido muy de lejos por aquellos que lo realizan en bicicleta $(8,1 \%)$ o caballo $(0,3 \%)$. Por otra parte, en el tipo de establecimiento elegido para alojarse, destaca el albergue público al que han acudido casi el $80 \%$ del total de los encuestados. Sin embargo en muchos casos, esta modalidad se ha combinado con otras como albergue privado, utilizado por el 57,3 \% de la muestra o, incluso, los alojamientos hoteleros $(15,7 \%)$. El camping $(2,6 \%)$ y la casa rural $(0,8 \%)$ son los menos frecuentados para hospedarse.

En cuanto a la evaluación específica de "la percepción de los caminantes sobre los efectos de la masificación en el Camino" se han elaborado dos tablas. En una se agrupan los ítems formulados de forma positiva (Tabla 4) y, en la otra, donde se incluyen los ítems revertidos (Tabla 5); recordemos que estos últimos ítems se caracterizan por formularse en positivo pero por interpretarse en dirección opuesta al rasgo latente y necesitan, de este modo, analizarse de manera separada.

En cuanto a los ítems positivos (Tabla 4), todos han sido valorados con una noła de 4 o superior. Destacan por encima del resto la "buena conservación del trazado" (4,20; DT 0,94), posicionándose casi el 80\% de la muestra "de acuerdo" o "totalmente de acuerdo" con esta afirmación y la "buena señalización de la ruta" $(4,19 ;$ DT 1,14) donde cerca de un 75\% (Tabla 6) de la muestra está de acuerdo con esta afirmación. Por detrás de estos, pero también con muy 
buena valoración se encontrarían la "amabilidad de los residentes" (4,11; DT 1,07) y la "buena conservación del patrimonio" (4; DT 1,09).

Tabla 4. Distribución de la muestra por tipología de establecimiento elegido.

\begin{tabular}{|l|c|c|c|}
\hline \multicolumn{1}{|c|}{$\begin{array}{c}\text { TIPO DE } \\
\text { ESTABLECIMIENTO }\end{array}$} & FRECUENCIAS & $\begin{array}{c}\text { PORCENTAIE DE } \\
\text { CASOS }\end{array}$ & $\begin{array}{c}\text { PORCENTAIE DE } \\
\text { RESPUESTAS }\end{array}$ \\
\hline $\begin{array}{l}\text { Alojamiento albergue } \\
\text { público }\end{array}$ & 305 & $79,8 \%$ & $51,1 \%$ \\
\hline $\begin{array}{l}\text { Alojamiento albergue } \\
\text { privado }\end{array}$ & 219 & $57,3 \%$ & $36,7 \%$ \\
\hline $\begin{array}{l}\text { Alojamiento } \\
\text { establecimiento } \\
\text { hotelero }\end{array}$ & 60 & $15,7 \%$ & $10,1 \%$ \\
\hline Alojamiento camping & 10 & $2,6 \%$ & $1,7 \%$ \\
\hline Alojamiento casa rural & 3 & $0,8 \%$ & $0,5 \%$ \\
\hline$N$ & 597 & $153,3 \% *$ & $100 \%$ \\
\hline
\end{tabular}

*Distribución porcentual según el número de casos.

Fuente: elaboración propia

Tabla 5. Valoración de los ítems positivos por parte de las personas que realizan el Camino de Santiago Francés

\begin{tabular}{|l|c|c|c|}
\hline & MIN-MÁX & MEDIA & DT \\
\hline Trazado bien conservado & $1-5$ & 4,20 & 0,94 \\
\hline Buena señalización & $1-5$ & 4,19 & 1,14 \\
\hline Residentes amables & $1-5$ & 4,11 & 1,07 \\
\hline Patrimonio bien conservado & $1-5$ & 4 & 1,09 \\
\hline N=385 & & & \\
\hline
\end{tabular}

Fuente: elaboración propia

Respecto a los ítems revertidos (Tabla 5) destacan por su baja puntuación y, por tanto, buena valoración, la "suciedad del Camino" $(2,18$ DT 1,17) y la existencia de "demasiadas colas en alojamientos y restaurantes" (2,32 DT 1,20), posicionándose los dos con una media inferior a 2,5. También, en cuanto a los ítems revertidos peor valorados y, por tanto, con una media más alta destacan la percepción de "demasiadas personas en la ruta", ya comentado, y la "pérdida de identidad original de la ruta" $(3,16$; DT 1,31). 
Tabla 6. Valoración de los ítems revertidos por parte de las personas que realizan el Camino de Santiago Francés

\begin{tabular}{|l|c|c|c|}
\hline & MIN-MÁX & MEDIA & DT \\
\hline Camino sucio & $1-5$ & 2,18 & 1,17 \\
\hline Alto precio de alojamientos & $1-5$ & 2,63 & 1,27 \\
\hline Alto precio restaurantes & $1-5$ & 2,69 & 1,31 \\
\hline Pérdida de la identidad original de la ruła & $1-5$ & 3,16 & 1,31 \\
\hline Demasiadas personas en la ruła & $1-5$ & 3,34 & 1,13 \\
\hline N=385 & & & \\
\hline
\end{tabular}

Fuente: elaboración propia

Es interesante también, analizar los datos relativos a las frecuencias donde se aprecia que más del $50 \%$ de la muestra afirma estar en "desacuerdo" o "totalmente en desacuerdo" con estas afirmaciones (Tabla 7).

Tabla 7. Distribución de frecuencias de los ítems de valoración de los impactos del turismo en el Camino de Santiago Francés

\begin{tabular}{|l|c|c|c|c|c|}
\hline & $\begin{array}{c}\text { TOTALMENTE } \\
\text { DESACUERDO }\end{array}$ & $\begin{array}{c}\text { EN } \\
\text { DESACUERDO }\end{array}$ & $\begin{array}{c}\text { NI DE } \\
\text { ACUERDO NI } \\
\text { DESACUERDO }\end{array}$ & $\begin{array}{c}\text { DE } \\
\text { ACUERDO }\end{array}$ & $\begin{array}{c}\text { TOTALMENTE } \\
\text { DE ACUERDO }\end{array}$ \\
\hline $\begin{array}{l}\text { Trazado bien } \\
\text { conservado }\end{array}$ & $0,78 \%$ & $4,94 \%$ & $16,88 \%$ & $28,31 \%$ & $49,09 \%$ \\
\hline $\begin{array}{l}\text { Buena } \\
\text { señalización }\end{array}$ & $3,64 \%$ & $7,53 \%$ & $13,25 \%$ & $17,66 \%$ & $57,92 \%$ \\
\hline $\begin{array}{l}\text { Residentes } \\
\text { amables }\end{array}$ & $3,64 \%$ & $5,45 \%$ & $13,77 \%$ & $30,91 \%$ & $46,23 \%$ \\
\hline $\begin{array}{l}\text { Patrimonio bien } \\
\text { conservado }\end{array}$ & $2,86 \%$ & $7,27 \%$ & $20,26 \%$ & $26,23 \%$ & $43,38 \%$ \\
\hline Camino Sucio & $37,14 \%$ & $27,01 \%$ & $21,30 \%$ & $9,87 \%$ & $4,68 \%$ \\
\hline $\begin{array}{l}\text { Alto precio de } \\
\text { alojamientos }\end{array}$ & $24,42 \%$ & $23,64 \%$ & $25,97 \%$ & $16,88 \%$ & $9,09 \%$ \\
\hline $\begin{array}{l}\text { Alto precio } \\
\text { restaurantes }\end{array}$ & $24,16 \%$ & $23,12 \%$ & $22,08 \%$ & $20,78 \%$ & $9,87 \%$ \\
\hline $\begin{array}{l}\text { Pérdida de la } \\
\text { identidad } \\
\text { original de la } \\
\text { ruta }\end{array}$ & $14,81 \%$ & $14,55 \%$ & $30,39 \%$ & $20,52 \%$ & $19,74 \%$ \\
\hline
\end{tabular}

Fuente: elaboración propia 
En lo que a los precios de los restaurantes y alojamientos se refiere, han sido valorados con una media inferior a 3, más concretamente de 2, 69 (DT 1,31) y 2, 63 (DT 1,27) respectivamente, siendo considerados como una oferta accesible desde el punto de vista económico. Por otro lado, en cuanto a la capacidad de acogida de estos restaurantes y alojamientos, se observa que la falta de alojamiento se valora con una media baja de 2,58 (DT 1,38) al igual que la existencia de colas en alojamientos y restaurantes $(2,32 ; \mathrm{dl} 1,20)$

Así pues, se puede afirmar que, en cuanto a la valoración que los caminantes hacen de los impactos que se producen en la ruta, los ítems relacionados con aspectos negativos del Camino son valorados con una puntuación más bien baja, con medias ligeramente superiores o inferiores a 3; mientras que aquellos cuyos ítems valoran rasgos más positivos son valorados con notas altas, con medias por encima de 4.

Respecto a la percepción de la masificación, se ha evaluado, en cambio, a través del ítem demasiadas personas y ha sido valorado con una media mayor de 3 (3,34; DT 1,13). Tal y como se ha explicado en el punto referente a la metodología y como mostraran autores como Shelby y Vaske (2007), se ha recategorizado en una variable dicotómica donde el 21\% de la muestra indica que no existe masificación en el camino, mientras el 78,44\% indican que perciben dicha masificación.

Tabla 8. Valoración de la percepción de masificación por parte de los caminantes

\begin{tabular}{|l|c|c|c|c|}
\hline & MEDIA & DT & $\begin{array}{c}\text { NO MASIFICADO } \\
\text { (VALORES DEL 1 AL 2) }\end{array}$ & $\begin{array}{c}\text { MASIFICADO } \\
\text { (VALORES DEL 3 AL 5) }\end{array}$ \\
\hline $\begin{array}{l}\text { Demasiadas personas en } \\
\text { la ruta }\end{array}$ & 3,34 & 1,13 & $21,56 \%$ & $78,44 \%$ \\
\hline
\end{tabular}

Fuente: elaboración propia

Tabla 9. Valoración de la percepción de masificación en las infraestructuras básicas del Camino de Santiago Francés

\begin{tabular}{|l|c|c|c|c|c|c|c|}
\hline & MEDIA & DT & 1 & 2 & 3 & 4 & 5 \\
\hline $\begin{array}{l}\text { Demasiadas colas en } \\
\text { alojamientos y } \\
\text { restaurantes }\end{array}$ & 2,32 & 1,20 & $32,81 \%$ & $24,74 \%$ & $26,04 \%$ & $10,68 \%$ & $5,73 \%$ \\
\hline Falta de alojamiento & 2,58 & 1,38 & $31,17 \%$ & $20,78 \%$ & $18,44 \%$ & $18,44 \%$ & $11,17 \%$ \\
\hline
\end{tabular}

Fuente: elaboración propia.

Para complementar la información relativa a la percepción de masificación, se han incluido dos ítems que hacen referencia a los lugares donde más aglomeraciones se producen según los expertos, los albergues y los alojamientos. No obstante, las respuestas relativas tanto a la existencia 
de demasiadas colas en alojamientos y restaurantes (2,32, DT 1,2) como a la falta de alojamiento $(2,58$ DT 1,38$)$ indican que no existen demasiados problemas en estas infraestructuras.

En lo que se refiere al umbral de capacidad de carga de los caminantes, se ha preguntado si los encuestados estarían dispuestos a abandonar la ruta por alguna de las cuestiones anteriores. La respuesta ha sido mayoritariamente negativa, pues un 77,7\% no dejaría la ruta por ninguna de las razones expuestas anteriormente (efectos de la masificación). No obstante, existe un 10,9\% que estaría dispuesto a abandonar la ruta por la existencia de demasiadas personas en la ruta, un 8,1\% por la falta de alojamiento y un 6 \% por la pérdida de identidad de la ruta.

\section{Tabla 10. Distribución de frecuencias de las razones por las cuales los caminantes estarían dispuestos a abandonar la ruta}

\begin{tabular}{|l|c|c|}
\hline & $\mathrm{N}$ & $\%$ \\
\hline Ninguna & 299 & $77,7 \%$ \\
\hline Demasiadas personas & 42 & $10,9 \%$ \\
\hline Falta de alojamiento & 31 & $8,1 \%$ \\
\hline Pérdida de identidad & 23 & $6,0 \%$ \\
\hline $\mathrm{N}$ & 385 & $100,0 \%$ \\
\hline
\end{tabular}

Fuente: elaboración propia

Mientras que el interés mostrado por repetir la experiencia, muestra un resultado muy positivo, el 90 \% indicó estar dispuesto a hacerlo de nuevo, revelando así un nivel de satisfacción muy alto.

Sin embargo, se ha querido profundizar en las características de la experiencia que estarían dispuestos a repetir, es decir, en la actitud que los caminantes tomarían en futuras ocasiones en función de su satisfacción con el viaje. En ese sentido, el 38 \% (146) declara que no modificaría su conducta en caso de masificación mientras que el 62 \% (239) restante sí que lo haría; de este $62 \%$ la mayoría acudiría en otra época del año (24\%) o elegiría otro camino distinto al francés (22\%), siendo una minoría los que realizarían este mismo camino pero tratando de evitar las zonas donde se produjeran más aglomeraciones de personas (13\%), o aquellos que no volverían más (3 \%).

Por último, se han medido los estándares de evaluación a través de la metodología PAOT y los resultados obtenidos (Tabla 11) muestran que el 56,4\% (217) de la muestra no podría admitir la imagen de máxima aglomeración recreada en la fotografía número 4 de la Figura 4, mientras que un 30,6\% (118) no estaría influido por estas aglomeraciones y admitiría todas las situaciones. Dentro de los resultados obtenidos sorprende, sin embargo, la respuesta de un 8,1\% (31) que huye de soledad total y no podría admitir una imagen en la que no hubiera personas. 
Tabla 11. Distribución de las actitudes que tomarán en futuras ocasiones en función de su experiencia

\begin{tabular}{|l|c|c|}
\hline \multicolumn{1}{|c|}{ ACTITUD FUTURA } & FRECUENCIA & PORCENTAJE \\
\hline No modifico conducta & 146 & $38 \%$ \\
\hline Volveré en otra época del año & 94 & $24 \%$ \\
\hline Elija otro camino distinto al francés & 86 & $22 \%$ \\
\hline Evitaré zonas más llenas de gente & 49 & $13 \%$ \\
\hline No vuelva al Camino & 10 & $3 \%$ \\
\hline N=385 & & \\
\hline
\end{tabular}

Fuente: elaboración propia

Tabla 12. Distribución de frecuencias de la evaluación de estándares de aglomeración

\begin{tabular}{|l|c|c|}
\hline & FRECUENCIA & PORCENTAJE \\
\hline Imagen 4 (Figura 4) & 217 & $56,4 \%$ \\
\hline Admitiría todas & 118 & $30,6 \%$ \\
\hline Imagen 1 (Figura 4) & 31 & $8,1 \%$ \\
\hline Imagen 3 (Figura 4) & 19 & $4,9 \%$ \\
\hline Total & 385 & $100,0 \%$ \\
\hline
\end{tabular}

Fuente: elaboración propia

\section{Discusión}

Partíamos de tesis opuestas esgrimidas en estudios teóricos respecto a la temática que, o bien defendían la existencia de masificación del Camino de Santiago (Gracia, 2005; Almeida, 2006; Santos, 2006; Tresserras, 2007; Fiol, 2010; Porcal et al., 2012; Alvarado, 2013; Martín-Duque, 2017) o, por el contrario, identificaban el Camino como un destino no masificado desde el punto de vista de la percepción (Santos \& Lois, 2011). A diferencia de estos estudios, la presente investigación plantea un análisis sistemático basado en el método de la evaluación de la capacidad de carga perceptual.

Los resultados empíricos muestran la complejidad del análisis de la capacidad de carga en un recurso dinámico como el Camino de Santiago francés (Murray \& Graham, 1997). La problemática planteada no admite una respuesta, tanto de sí o no, sino de tendencias, de evoluciones y de matices. Así, se ha identificado que alrededor del $70 \%$ de la muestra considera que hay demasiadas personas en la ruta lo que, de acuerdo con la tesis de Shelby y Herbelein en 1986 
(más de dos tercios de los visitantes se sienten masificados quiere decir que se ha excedido la capacidad de carga), viene a mostrar que estamos ante un escenario de masificación. Un escenario que refleja la realidad del Camino en la época de más afluencia, de tal modo que no podemos trasladar este escenario a temporadas de menor afluencia. ${ }^{8}$

Sin embargo, hay que matizar este escenario de la masificación con resultados más detallados. En efecto, en la percepción de masificación en las infraestructuras de alojamiento y restauración que son los lugares donde más aglomeraciones se producen según los expertos (Martín-Duque, 2017), los resultados obtenidos no nos permiten confirmar esta afirmación. Más aún, en lo que se refiere a la percepción que los caminantes tienen de los impactos que el turismo genera en el itinerario, se aprecia que, en general, es bastante favorable, siendo especialmente positiva la percepción de la limpieza y la conservación general del Camino y de los recursos que lo componen. Estos buenos resultados pueden estar relacionados con la buena actitud de los turistas en el Camino, señalada tanto por expertos del camino (Martín-Duque, 2017) como por la alta satisfacción de los peregrinos (Santos \& Lois, 2011; Fernández \& Riveiro, 2018). Otro de los motivos para esta buena conservación puede residir en el esfuerzo tanto de asociaciones como de instituciones públicas respecto a la conservación de la ruta y la accesibilidad de la misma (Santos, 2006, 2012). De esta manera se aprecia cómo, pese a un aumento del número de caminantes, una buena gestión a escala local está mitigando los efectos y la percepción de la masificación.

Por otro lado, cerca de un $80 \%$ de la muestra admite que no abandonaría la ruta por ninguno de los impactos expuestos en este estudio (demasiadas personas, colas en alojamientos, Camino muy sucio...etc.), lo que indicaría que no ha rebasado su umbral de capacidad de carga actual. No obstante, existe un 10,9\% que estaría dispuesto a abandonar la ruta por la existencia de demasiadas personas en la ruta, un 8,1\% por la falta de alojamiento y un $6 \%$ por la pérdida de identidad de la ruta. También, vemos un número no despreciable $(22,3 \%)$ que estaría dispuesta a abandonar la ruta si las variables "existencia de demasiadas personas", "falta de alojamiento" y "pérdida de identidad de la ruta" superaran los límites para ellos aceptables. Coincide, por tanto, con el estudio de Kuentzel y Heberlein (1992) que afirman que la experiencia de masificación no influye en el abandono del destino, pero sí en un cambio de conducta del visitante.

Algo está cambiando y la masificación se está comenzando a hacer perceptible. En este sentido, cabe destacar que, si bien no hay estudios que lo demuestren, cada vez aparecen más noticias en prensa que indican la falta de alojamiento patente en la ruta (Deaño Santiago, 2017, August 3) y la creciente masificación (EFE Santiago, 2014, January 17; EFE Santiago, 2017, May 6). De hecho,

8 Hay que tener en cuenta que el estudio se ha llevado a cabo en los 100 últimos kilómetros, donde más caminantes hay. Eso, que podría ser un sesgo de la investigación resulta ser un objetivo al querer conocer el tramo más "congestionado", en la época de mayor masificación, tomando como mes de referencia el mes de agosto. 
cuando analizamos la conducta futura de los encuestados, la mayoría de los encuestados (un 62\%) sí que estaría dispuesta a cambiar su conducta en futuras ocasiones e, incluso, un 3\% no volverían más; el tema no les es extraño y buscan un destino que responda a sus expectativas. De hecho, en cuanto a los estándares de evaluación, es decir aquellas normas que nos permiten deducir "cuántas personas son demasiadas" (Manning et al., 2005) hay que indicar que para cerca del $60 \%$, las imágenes 3 y 4 , donde se aprecia el Camino con una cierta cantidad de personas, sería una situación inadmisible y, por tanto, considerarían que se ha sobrepasado la capacidad de carga. Este dato nos permite afirmar, de nuevo, que una mayoría de la muestra es sensible a la masificación. En esta línea, podría ser interesante plantear para futuras investigaciones diferentes perfiles de personas que realizan el camino en función de sus estándares de evaluación, tal y como se ha hecho en otros estudios (Navarro et al., 2013).

Así, se comprende mejor la importancia de los impactos y de la masificación si tenemos en cuenta las características del Camino de Santiago y los resultados de los estudios especializados acerca de las motivaciones. Se comprueba que son muchas las personas que lo consideran como una experiencia personal o un reto, tal y como señalan Granero, Ruiz y García (2005). En la misma línea, otros autores (López et al., 2017; Amaro, et al., 2018), hacen hincapié en la transformación de las personas que realizan el Camino como buscadores de experiencias espirituales transformadoras. La singularidad de dichas motivaciones podría explicar que no estuvieran dispuestos a abandonar.

Sin embargo, el Camino está cambiado, al menos en la percepción de su identidad por parte de los caminantes. La alta media $(3,14)$ que recoge el ítem referido a la pérdida de identidad junto con el elevado porcentaje que está de acuerdo con esta afirmación (más del 40\% de la muestra) denota el cambio que ha experimentado el Camino en los últimos años. Una transformación que ha podido cambiar su esencia original y que puede indicar que el itinerario está experimentando una posible transformación en su esencia como Camino de Santiago Francés (Gracia, 2005), lo que puede influir de forma negativa en la percepción de capacidad de carga (Navarro et al., 2013) o incluso, derivar en un proceso de aculturación, tal y como indican Coccossis y Mexa (2002), la OMT (2005) o Mason (2009).

\section{Conclusiones}

Hemos analizado el Camino de Santiago francés, ruta que tiene un gran reconocimiento internacional, con un gran número de caminantes que la recorren año tras año también muy heterogéneos. El crecimiento del número de caminantes ha llevado a que se estén escuchando voces sobre la masificación en el Camino, voces que han ido apareciendo en la prensa, o por parte de expertos y las asociaciones jacobeas con la elaboración del "Manifiesto de Villafranca del Bierzo" adhiriéndose a la petición del ICOMOS-España para solicitar la inclusión inmediata del 
Camino Francés en la Lista del Patrimonio Mundial en Peligro de la UNESCO. Por ello, se hacía indispensable planear un estudio científico y empírico sobre la capacidad de carga en el Camino, escogiendo el enfoque perceptual por las características del Camino, al no estar ante un recurso acotado sino ante una suma de recursos unidos por un trayecto. Los resultados obtenidos han aportado información valiosa, además de esclarecer algunas cuestiones relativas a las características de estos caminantes que inciden directamente en esta percepción, que pueden ayudar a comprender la viveza de esta Camino así como a la adopción de medidas. En efecto, al establecer un diagnóstico a través de la capacidad de carga desde un enfoque perceptual, se ha creado una ayuda y herramienta para los gestores.

Se puede afirmar, por tanto, que estamos ante un turista que tiene, en general, una imagen positiva de los impactos que se están produciendo en el Camino como consecuencia de la afluencia de turistas al mismo. No obstante, una parte significativa de ellos, están percibiendo algunos síntomas de masificación en la ruta que, a un escaso grupo, les haría abandonar el Camino. Incluso, parte de ellos son sensibles a la masificación y estarían dispuestos a dejar la ruta por la existencia de demasiadas personas, o a cambiar su conducta futura. Todavía la percepción de la masificación no es alta por una buena gestión del Camino a nivel local que está reduciendo los efectos del incremento de viajeros.

Pese a que la investigación se ha llevado a cabo en las etapas finales del Camino más masificadas y en temporada alta (mes de agosto) la imagen es todavía positiva. El grado de masificación o, más bien, unas perspectivas que hay que tomarse con cautela y con cierta preocupación es la diferencia entre las motivaciones y la propia experiencia de los caminantes, donde se percibe una gran brecha y tiene que hacer pensar a todos los protagonistas y gestores turísticos. En ese sentido si el peso del imaginario construido y de los espacios conocidos es fuerte en relación con la propia experiencia, nos encontramos con un camino que posee una muy fuerte imagen y que, sin embargo, empieza a debilitarse en la propia experiencia.

Por otra parte, existe un factor a tener en cuenta es el del efecto constante de los caminantes sobre el destino, con la transformación y su cambio identitario. Este factor tiene que ser considerado en la gestión del Camino. Solo nos queda recordar las propuestas realizadas por asociaciones de peregrinos en cuanto a la variación de las reglas para la obtención de la Compostela o la promoción de alojamientos que puedan suponer una alternativa a los alojamientos públicos, dentro de un planteamiento sostenible.

Sin embargo, para una mejor comprensión de este fenómeno será necesario abordar futuros estudios en los que se estudien estas posibles soluciones con más profundidad, en otros tramos por ejemplo así como desde metodologías complementarias. Asimismo, este estudio abre la puerta a un análisis más profundo en el que se puedan identificar diferentes tipos de caminantes en función 
de sus estándares de evaluación así como de su percepción de la masificación. Por otra parte, la certeza de que el Camino va a ir variando en el tiempo, en paralelo con la evolución de los caminantes manifiesta la necesidad de seguir realizando estudios sobre esta temática. Tantas variables que piden una dedicación investigadora constante y a largo plazo a este destino paradigmático del turismo.

Declaración responsable: Las autoras declaran que no existe ningún conflicto de interés en relación con la publicacion de este artículo. Las tareas se han distribuido de la siguiente manera: el artículo ha sido coordinado por C. Martín. Las dos autoras han participado en la revisión bibliográfica, conclusiones y futuras líneas de investigación. La elaboración de la base de datos, trabajo de campo y análisis cuantitativo fueron realizados por C. Martín, fruto de su tesis doctoral. 


\section{Bibliografía}

Almeida, F. (2006). Tipología de visitante turístico y satisfacción de la experiencia turística en Santiago de Compostela. Baetica. Estudios de Arte Geografía e Historia, 28, 231-258. http://dx.doi.org/10.24310/baetica.2006.v1i28.260

Alonso, F. (2009). Santiago y los Caminos de Santiago: un paisaje cultural, una cultura del paisaje. Boletín de la Asociación de Geógrafos Españoles, 51, 203-208. https://www.agegeografia.es/ojs/index.php/bage/article/view/1138

Álvarez, A. (2007). El Camino de Santiago como patrimonio a poner en valor. In Actas del V Congreso Internacional "Restaurar la memoria", patrimonio y territorio (pp. 87-112). Valladolid 2006.

Amaro, S., Antunes, A., \& Henriques, C. (2018) A closer look at Santiago de Compostela's pilgrims through the lens of motivations. Tourism Management, 64, 271-280. https://doi.org/10.1016/j.tourman.2017.09.007

Arnberger, A., \& Brandenburg, C. (2007). Past On-Site Experience, Crowding Perceptions, and Use Displacement of Visitor Groups to a Peri-Urban National Park. Environmental Management, 40(1), 34-45. http://dx.doi.org/10.1007/s00267-004-0355-8

Arnberger, A., \& Haider, W. (2005). Social effects on crowding preferences of urban forest visitors. Urban Forestry and Urban Greening, 3, 125-136. http://dx.doi.org/10.1016/j.ufug.2005.04.002

Bermejo, $M^{a}$ (2002). La protección de los itinerarios culturales: en especial la protección del camino de Santiago a través de las técnicas protectoras del patrimonio histórico. In IV Congreso de Turismo Universidad y Empresa. La diversificación y la desestacionalización del sector turístico (pp. 337350). Tirant lo Blanch.

Butler, R. (1996). The Concept of Carrying Capacity for Tourism Destinations: Dead or Merely Buried? Progress in Tourism and Hospitality Research, 2(3-4), 283-293. http://dx.doi.org/10.1002/pth.6070020309

Canales, M. (2006). Metodologías de la investigación social. Santiago, Chile: LOM Ediciones.

Celeiro, L. (2014). Xacobeo 93: el renacer del Camino. In S. Novello, F. Martínez, P. Murias \& J. C. De Miguel (Eds.), Xacobeo. De un recurso a un evento turístico global (pp. 180-191). Spain: Andavira Editora. 
Coccossis, H., \& Mexa, A. (2002). Defining, measuring and evaluating carrying capacity in European tourism destinations (Report B4-3040/2000/294577/MAR/D2). Athens: Environmental Planning Laboratory by the European Commission, Directorate-General for Environment, Nuclear Safety and Civil Protection. Retrieved from

http://ec.europa.eu/environment/iczm/pdf/tcca_en.pdf

Coccossis, H. (2004). Sustainable Tourism and Carrying Capacity: a New Context. In H. Coccossis \& A. Mexa (Eds.), The Challenge of tourism carrying capacity assessment (pp. 37-53). Burlington: Ashgate.

Collins-Kreiner, N. (2010). Researching pilgrimage. Continuity and Transformation, Annals of Tourism research, 37, 440-456.

Culturabase (2018). Turismo cultural en 2017. Retrieved from http://www.mcu.es/culturabase/cgi/um? $M=/+7 / p 7 b \& O=$ culturabase $\& N=\& L=0>$

Echamendi, P. (2001). La capacidad de carga turística. Aspectos conceptuales y normas de aplicación. Anales de Geografía de la Universidad Complutense, 21, 11-30.

Santiago. Elcorreogallego.es Retrieved from http://www.elcorreogallego.es/santiago/ecg/navacastro-desea-fomentar-un-turismo-sostenible-camino-santiago/idEdicion-2017-05-06/idNoticia$\underline{1054022 /}$

Deaño Santiago, C. (2017, August 3). Problemas de alojamiento en Santiago por la llegada de grupos de peregrinos. Elcorreogallego.es Retrieved from http://www.elcorreogallego.es/santiago/ecg/problemas-alojamiento-santiago-llegada-gruposperegrinos/idEdicion-2017-08-13/idNoticia-1068823/

EFE Santiago (2014, January 17). La masificación de gente desvirtúa el Camino de Santiago. El País. Retrieved from https://elpais.com/ccaa/2014/01/17/galicia/1389962964_798217.html

EFE Santiago (2017, May 6). Nava Castro desea fomentar un turismo "sostenible" en el Camino de Fernández, M., \& Riveiro, D. (2018) Estudio del impacto socioeconómico del Camino de Santiago. Universidad de Santiago de Compostela \& Axencia de Turismo de Galicia

Figuerola, M. (2017). Cuaderno de Coyuntura Turística. In Mesa del Turismo. Retrieved from https://mesadelturismo.org/wp-content/uploads/2017/10/Coyuntura-tur\%C3\%ADstica-Octubre2017.pdf

Fiol, J. (2010). El Camino Catalán de Santiago desde Montserrat. Cataluña: Lectio.

Fraternidad Internacional del Camino de Santiago (2014). Manifiesto de Villafranca del Bierzo. I Foro Internacional "El Legado de Elías Valiña". Villafranca del Bierzo: FICS. 
García, M., \& De la Calle, M. (2012). Capacidad de carga en grandes recursos turístico-culturales. Anales de Geografía, 32(2), 253-274.

Gravari-Barbas, M., Bourdeau, L., \& Robinson, M. (2015). World Heritage and tourism: from opposition to co-production. In L. Bourdeau, M. Gravari-Barbas, M. Robinson (Eds), World Heritage, Tourism and Identity. Inscription and Co-production. Routledge.

Getz, D. (1983). Capacity to absorb tourism: Concepts and implications for strategic planning. Annals of Tourism Research, 10(2), 239-263.

Gigirey, A. (2003). Turismo cultural en espacios sagrados desde la perspectiva de los residentes. Un estudio de la Catedral de Santiago de Compostela. Estudios Turísticos, 158, 79-108.

Gonson, C., Pelletier, D., \& Alban, F. (2018). Social carrying capacity assessment from questionnaire and counts survey: Insights for recreational settings management in coastal areas. Marine Policy, 98, 146-157. http://dx.doi.org/10.1016/j.marpol.2018.08.016

Gracia, J. (2005). El Camino de Santiago en el nuevo milenio. Fayuela: revista de estudios calceatenses, 1, 57-66.

Granero, A., Ruiz, F., \& García, Ma (2005). E. El Camino de Santiago como sendero de gran recorrido en la naturaleza. Revista digital Efdeportes, 10(87). Retrieved from http://www.efdeportes.com/efd87/camino.htm

Granero, A., Ruiz, F., García, Ma E., Baena, A., \& Gómez, M. (2008). Análisis del perfilsociodemográfico de senderistas y ciclistas que recorren el Camino de Santiago. Retos. Nuevas tendencias en Educación Física, deporte y Recreación, 13, 55-59.

Gunn, C. A. (1979). Tourism Planning. Nueva York: Russack \& Company.

Gutiérrez, J. (2013). El turismo que vemos y contamos. Técnicas de investigación social aplicadas al turismo. Madrid: UNED.

Hernández, J. (2011). Los caminos del patrimonio. Rutas turísticas e itinerarios culturales. Pasos. Revista de Turismo y Patrimonio Cultural, 9(2), 225-236.

ICOMOS (2006). Encuentro científico internacional sobre Itinerarios Culturales. Identificación, promoción e Inventario de Itinerarios Culturales. In Actas del Comité Científico International de Itinerarios Culturales (CIIC), 2. Ferrol, October 1-3.

INE (2018). Número de turistas según comunidad autónoma de destino principal. Estadística de movimientos turísticos en frontera. Frontur. Retrieved from https: / / www. ine.es/jaxiT3/Tabla.htm?t=23988\&L=0 
Kalisch, D. (2012). Relevance of crowding effects in a coastal National Park in Germany: results from a case study on Hamburger Hallig. Journal of Coastal Conservation, 16(4), 531-541. http://dx.doi.org/10.1007/s11852-012-0195-2

Kuentzel, W. F., \& Heberlein, T. A. (1992). Cognitive and Behavioral Adaptations to Perceived Crowding: A Panel Study of Coping and Displacement. Journal of Leisure Research, 24(4), 377393. http://dx.doi.org/10.1080/00222216.1992.11969903

Kuentzel, W. F., \& Heberlein, T.A. (2003). More visitors, Less crowding: Change and Stability of Norms Over Time at Apostole Islands. Journal of Leisure Research, 35(4), 349-371. http://dx.doi.org/10.1080/00222216.2003.11950001

Lee, H., \& Graefe, A. R. (2003). Crowding at an arts festival: extending crowding models to the frontcountry. Tourism Management, 24, 1-11. http://dx.doi.org/10.1016/s0261$\underline{5177(02) 00036-5}$

Leira, J., Rego, G., \& Santos, M. P. (2010). Peregrinaciones y turismo. El Camino de Santiago. Revista de ocio y turismo (Rotur), 3, 39-48.

López, L., \& Lois, R.C. (2015). El origen del turismo viajero italiano a lo largo del Camino de Santiago. Investigaciones Turísticas, 9, 132-159. http://dx.doi.org/10.14198/inturi2015.9.06

Lois, R. C., \& López, L. (2012). El Camino de Santiago: una aproximación a su carácter polisémico desde la geografía cultural y el turismo. Documents d’Anàlisi Geogràfica, 58(3), 459-479. Retrieved from http://hdl. handle.net/11441/16087

Lois-González, R.C., \& Santos, X.M. (2014). Tourists and Pilgrims on Their Way to Santiago. Motives, Caminos and Final Destinations. Journal of Tourism and Cultural Change, 13(2), 149-164. http://dx.doi.org/10.1080/14766825.2014.918985

López, L., Lois, R. C., \& Fernández, B. M. C. (2017). Spiritual tourism on the way of Saint James the current situation. Tourism Management Perspectives, 24, 225-234. http://dx.doi.org/10.1016/j.tmp.2017.07.015

Maak, K. (2009). El Camino de Santiago como posible motor turístico en zonas rurales de escasos recursos: el caso de Brandeburgo. Cuadernos de Turismo, 23, 149-171. Retrieved from https://revistas.um.es/turismo/article/view/70081

Manning, R. E., Freimund, W. A., Lime, D. W., \& Pitt, D. G. (1996). Crowding norms at frontcountry sites: A visual approach to setting standards of quality. Leisure Sciences, 18(1), 39-59. http://dx.doi.org/10.1007/s00267-002-2772-x 
Manning, R., \& Lawson, S. (2002). Carrying Capacity as "Informed Judgment": The Values of Science and the Science of Values. Environmental Management, 30(2), 157-168. http://dx.doi.org/10.1007/s00267-002-2772-x

Manning, R., Leung, Y., \& Budruk, M. (2005). Research to Support Management of Visitor Carrying Capacity of Boston Harbor Islands. Northeasen Naturalist, 12(3), 201-220. https://doi.org/10.1656/1092-6194(2005)12[201:rtsmov]2.0.co;2

Mansfeld, Y., \& Jonas, A. (2005). Evaluating the socio-cultural carrying capacity of rural tourism communities: a "value stretch" approach. Tijdchrift voor Economische en Sociale Geografie, 97(5), 583-601. https://doi.org/10.1111/j.1467-9663.2006.00365.x

Martín, C. (2014). El Camino de Santiago primitivo a su paso por Asturias, estudio de una ruta cultural desde una perspectiva turística. Cuadernos de Turismo, 33, 233-249. Retrieved from https://revistas.um.es/turismo/article/view/195721

Martín-Duque, C. (2017). Los impactos del turismo en el Camino de Santiago Francés: una aproximación cualitativa. Methaodos. Revista de ciencias sociales, 5(1), 62-73. http://dx.doi.org/10.17502/m.rcs.v5i1.155

Mason, P. (2005). Tourism Impacts, Planing and Management. Oxford: Elseiver Butterworth Heinemann.

Mc. Cool, S. F., \& Lime D. W. (2001). Tourism Carrying Capacity: Tempting Fantasy or Useful Reality? Journal of Sustainable Tourism, 9(5), 372-388.

http://dx.doi.org/10.1080/09669580108667409

Millán, Ma. G., Morales, E., \& Pérez, L. Ma. (2010). Turismo religioso: estudio del Camino de Santiago. Gestión Turística, 13, 9-37. http://dx.doi.org/10.4206/gest.tur.2010.n13-01

Montes, C. (2015). Al andar se hace turismo: nuevas ruralidades en torno al Camino de Santiago. Aposta. Revista de Ciencias Sociales, 65, 131-150.

Murray, M., \& Graham, B. (1997). Exploring the dialectics of route-based tourism: the Camino de Santiago. Tourism Management, 18(8), 513-524. http://dx.doi.org/10.1016/s02615177(97)00075-7

Navarro, E., Damian, I. M., \& Fernández, A. (2013). Carrying Capacity model applied in coastal destinations. Annals of Tourism Research, 43, 1-19. http://dx.doi.org/10.1016/j.annals.2013.03.005

Neuts, B.. \& Nijkamp, P. (2012). Tourist Crowding Perception and Acceptability in Cities: An Applied Modelling Study on Bruges. Annals of Tourism Research, 39(4), 2133-2153. http://dx.doi.org/10.1016/j.annals.2012.07.016 
O'Reilly, A. M. (1986). Tourism carrying capacity: concepts and issues. Tourism Management, 7, 254-258. http://dx.doi.org/10.1016/b978-0-7506-7789-9.50017-0

Oficina del Peregrino (2019). Informe estadístico Año Santo 2018. Retrieved from http://www.peregrinossantiago.es/esp/wp-content/uploads/informes/peregrinaciones2013.pdf

OMT. (2005). Indicadores de desarrollo sostenible para los destinos turísticos. Guía práctica. Madrid: OMT.

World Tourism Organization (UNWTO) (2017). UNWTO Tourism Highlights: 2017 Edition. http://dx.doi.org/10.18111/9789284419029

World Tourism Organization (UNWTO) (2018). Tourism Highlights. 2018 Edition. htp://dx.doi.org/10.18111/9789284419685

Pedersen, A. (2002). Managing Tourism at World Heritage Sites. World Heritage a practical Manual for World Heritage Site Managers. Paris: UNESCO.

Precedo, A., Revilla, A., \& Míguez, A. (2007). El turismo cultural como factor estratégico de desarrollo: el camino de Santiago. Estudios geográficos, LXVIII(262), 204-234.

Porcal, M. C., Diez, A., \& Junguitu, J. (2012). Dimensión territorial y turística de la Ruta Norte del Camino De Santiago en el País Vasco: distintas concepciones, valoraciones y propuestas de intervención sobre un fenómeno multifacético. Boletín de la Asociación de Geógrafos Españoles, 58, 177-204. http://dx.doi.org/10.21138/bage.2064

Rodríguez, M., \& Singul, F. (2004). Los Caminos de Santiago en Galicia. Galicia: Xunta de Galicia.

Rodríguez, M., Martínez, V.A., \& Junatey, O. (2011). Función de la comunicación en la promoción y desarrollo del evento Xacobeo y su influencia en el posicionamiento de Galicia como destino turístico. Hologramática, 14, 93-115.

Santos, X. M. (2006). El Camino de Santiago: Turistas y Peregrinos hacia Compostela. Cuadernos de Turismo, 18, 135-150. Retrieved from https://revistas.um.es/turismo/article/view/17791

Santos, X., \& Lois, R (2011). El Camino de Santiago en el contexto de los nuevos turismos. Estudios Turísticos, 189, 87-110.

Santos, X. M. (2012). Los turismos de interior en Galicia. Balance y perspectivas. Polígonos. Revista de Geografía, 23, 213-234. http://dx.doi.org/10.18002/pol.v0i23.541

Shelby, B. (1976.). Social psychological effects of crowding in wilderness: the case of River Trips in the Grand Canyon. Colorado: University of Colorado. 
Shelby, B. (1980). Contrasting recreational experiences: Motors and oars in the Grand Canyon. Journal of Soil and Water Conservation, 35, 129-131.

Shelby, B., \& Heberlin, T. (1986). Carrying capacity in recreation settings. Oregon: Oregon State University Press.

Shelby, B., \& Vaske, J. J. (2007). Perceived Crowding among Hunters and Anglers: A MetaAnalysis. Human Dimensions of Wildlife, 12, 241-261.

http://dx.doi.org/10.1080/10871200701460603

Somoza, X., \& Lois, R. C. (2017). Ordenación del Territorio y estrategias de planificación en los Caminos de Santiago Patrimonio Mundial. Investigaciones Geográficas, 68, 47-63. http://dx.doi.org/10.14198/INGEO2017.68.03

Stokols, D. (1972). On the distinction between density and crowding: some implications for future research. Psychological Review, 79(3), 275-277.

Stokols, D., Rall, M., Pinner, B., \& Schopler, J. (1973). Physical, social, and personal determinants of the perception of crowding. Enviroment and Behavior, 5, 87-115.

Tarrant, M.A., \& English. D. K. A. (1996). Crowding-based Model of Social Carrying Capacity: Applications for Whitewater Boating Use. Journal of Leisure Research, 28(3), 155-168. http://dx.doi.org/10.1080/00222216.1996.11949768

Tresserras, J. (2007). El Camino de Santiago: la gestión sostenible de un itinerario cultural transnacional, en VII Jornada sobre la Gestión Sostenible del Patrimonio: "Los itinerarios culturales y la formación de Europa". Fundació Abertis. Retrieved from http://www.fundacioabertis.org/rcs_jor/pdf_tresserras.pdf

Troitiño, M. A., \& Troitiño, L. (2016). Patrimonio y turismo: reflexión teórico-conceptual y una propuesta metodológica integradora aplicada al municipio de Carmona (Sevilla, España). Scripta Nova, XX(543), 1-45. https://doi.org/10.1344/sn2016.20.16797

Vaske, J. J., Donnelly, M. P., \& Heberlein, T. A. (1980). Perception of crowding and resource quality. Leisure Sciences, 3(4), 367-381.

Vaske, J. J., \& Shelby, B. (2008). Crowding as a Descriptive Indicator and an Evaluative Standard: Results from 30 Years of Research. Leisure Sciences, 30, 111-126. http://dx.doi.org/10.1080/01490400701881341

Watson, G. L., \& Kopachevsky, J. P. (1996). Tourism Carrying Capacity A critical look at the discursive dimension. Progress in Tourism and Hospitality research, 2, 169-179. https://doi.org/10.1002/pth.6070020205 
Williams, P. W., \& Gill, A. (1994). Tourism carrying capacity management issues. Global Tourism.

The next decade. In William Theobald. The Business of Tourism Management (pp. 174-187). Oxford: Butterworth-Heinemann. 